\title{
Role of DJ-1 in Immune and Inflammatory Diseases
}

\author{
Lulu Zhang, Jincheng Wang, Jiajia Wang, Bo Yang, Qiaojun He and Qinjie Weng* \\ Center for Drug Safety Evaluation and Research, College of Pharmaceutical Sciences, Zhejiang University, Hangzhou, China
}

The DJ-1 protein, known as an oxidative stress sensor, participates in the onset of oxidative stress-related diseases such as cancer, neurodegenerative disorders, type 2 diabetes, and male infertility. Although DJ-1 has been extensively studied for more than two decades, evidence has only recently emerged that it plays a key role in immune and inflammatory disorders. The immune regulatory function of DJ-1 is achieved by modulating the activation of several immune cells including macrophages, mast cells, and $T$ cells via reactive oxygen species (ROS)-dependent and/or ROS-independent mechanisms. This review describes the current knowledge on DJ-1, focusing on its immune and inflammatory regulatory roles, and highlights the significance of DJ-1 as a novel therapeutic target for immune and inflammatory diseases.

\section{OPEN ACCESS}

Edited by:

Sermin Genc,

Dokuz Eylul University, Turkey

Reviewed by:

Mark Wilson,

University of Nebraska-Lincoln,

United States

Yuji Kaneko,

University of South Florida,

United States

*Correspondence:

Qinjie Weng

wengqinjie@zju.edu.cn

Specialty section:

This article was submitted to

Inflammation,

a section of the journal

Frontiers in Immunology

Received: 23 January 2020 Accepted: 27 April 2020

Published: 16 June 2020

Citation:

Zhang L, Wang J, Wang J, Yang B, He $Q$ and Weng $Q$ (2020) Role of

DJ-1 in Immune and Inflammatory

Diseases. Front. Immunol. 11:994.

doi: 10.3389/fimmu.2020.00994
Keywords: DJ-1, ROS, immune diseases, inflammatory diseases, therapeutic target

\section{INTRODUCTION}

The DJ-1 gene was originally discovered as an oncogene that shows transforming activity in conjunction with the ras gene and was later identified as a causative gene for autosomal recessive, early-onset Parkinson's disease (PD), PARK7 (1,2). As a multifunctional protein, DJ-1 can regulate transcription and signal transduction pathways, scavenge reactive oxygen species (ROS), and function as a molecular chaperone and enzyme, all of which leads to the anti-oxidative stress reaction of DJ-1 (3-7). In addition to the participation of DJ-1 in cancer and PD, a great number of studies have indicated that DJ-1 is also involved in the pathogenesis of multiple oxidative stressassociated diseases including stroke, male infertility, neurodegenerative diseases, and diabetes mellitus (8-11).

Recently, accumulating evidence has indicated that DJ-1 exerts immune and inflammatory regulatory functions by modulating the activation of several immune cells such as macrophages, mast cells (MCs), and T cells via ROS-dependent and/or ROS-independent mechanisms (12-14). In this review, we discuss the role of DJ-1 in the physiopathology of several immune and inflammatory diseases including sepsis, allergic diseases, atherosclerosis (AS), and multiple sclerosis (MS), highlighting DJ-1 as a potential therapeutic target for immune and inflammatory diseases.

\section{GENE, PROTEIN, AND MOLECULAR CHARACTERISTICS OF DJ-1}

The human DJ-1 gene (PARK7) maps on chromosome 1 at $1 \mathrm{p} 36.23$ according to Entrez Gene, and the mouse homolog is found on chromosome 4E. Containing 17 distinct gt-ag introns and 7 exons, $D J-1$ encompasses $23.86 \mathrm{~kb}$ (15). Through alternative promoters and alternative splicing, 17 different variants from the gene have been reported (15). Among these, 15 transcripts have proteincoding potential, while 2 transcript variants encoding the same protein have been identified for this gene (15). 
Comprising 189 amino acid residues, human DJ-1 is a small $(20 \mathrm{kDa})$ protein that belongs to the large DJ-1/ThiJ/PfpI superfamily, which is ubiquitously expressed in more than 22 human tissues including the pancreas, kidney, skeletal muscle, liver, testis, and heart (16). During the course of many years, the DJ-1/ThiJ/PfpI superfamily has been found in diverse organisms from bacteria to humans (16). Although not all members of this superfamily have been characterized structurally, 61 structures of human DJ-1 that were determined by X-ray crystallography have been deposited in the Protein Data Bank as of January 2020, indicating that it exists as a dimer (17). The structure of the DJ-1 monomer has a helix-fold-helix flavodoxin-like fold, with $11 \beta$ strands $(\beta 1-\beta 11)$ and $8 \alpha$-helices $(\alpha \mathrm{A}-\alpha \mathrm{H})$ (18). It centers on a $\beta$-sheet that contains six parallel strands arranged regularly and surrounded by $\alpha$-helices, and $\beta 3-4$ that form a hairpin structure that contributes to its dimerization (17-19). In addition, dimeric DJ-1 characterizes a different arrangement of the $\alpha \mathrm{A}$ and $\alpha \mathrm{H}$ helices of the two monomers from other members of this superfamily (17). However, the L166P (Leu ${ }^{166}$ Pro) mutation of DJ-1, which is located in the center of $\alpha \mathrm{G}$ and linked to familial PD, confers reduced protein stability and interferes with homodimerization (20).

DJ-1 seems to act primarily as a redox-sensitive chaperone and sensor for imbalanced cellular redox state, since its overexpression is induced by a variety of oxidative agents such as paraquat, lipopolysaccharide (LPS), iron, hydrogen peroxide $\left(\mathrm{H}_{2} \mathrm{O}_{2}\right)$, 6-hydroxydopamine, ultraviolet irradiation, and high glucose, protecting multiple kinds of cells including endothelial cells, macrophages, fibroblast cells, neurons, cancer cells, and islet $\beta$ cells $(11,21-25)$. Deletion of $D J-1$ augments cell death by oxidative stress, endoplasmic reticulum stress, and proteasome inhibitors (6).

\section{THE MULTIFACETED ROLES OF DJ-1 AS AN ANTIOXIDANT \\ Reduced and Oxidized Forms of DJ-1 and Their Functions}

DJ-1 functions as an antioxidant through various mechanisms, including scavenging ROS in a manner dependent on three redox-sensitive cysteine residues at amino acids 46, 53, and 106 (C46, C53, and C106, respectively). Of these, C106 is considered the most oxidative stress-sensitive residue and is sequentially oxidized to form sulfenic acid $(\mathrm{SOH})$, sulfinic acid $\left(\mathrm{SO}_{2} \mathrm{H}\right)$, and sulfonic acid $\left(\mathrm{SO}_{3} \mathrm{H}\right)(5)$. DJ-1 exhibits distinct properties and functions dependent on the oxidation state of C106. Moderate oxidation of $\mathrm{C} 106$ to $\mathrm{SO}_{2} \mathrm{H}$ is responsible for mitochondrial

Abbreviations: AS, atherosclerosis; ASK1, apoptosis signal-regulating kinase 1; CXCR4, chemokine receptor 4; Daxx, death-associated protein 6; EAE, experimental autoimmune encephalomyelitis; $\mathrm{H}_{2} \mathrm{O}_{2}$, hydrogen peroxide; Hsp70, heat shock protein 70; Keap1, Kelch-like ECH-associated protein 1; KO, knockout; LPS, lipopolysaccharide; MAPKs, mitogen-activated protein kinases; MCs, mast cells; MS, multiple sclerosis; NF- $\kappa$ B, nuclear factor kappa B; NHE1, $\mathrm{Na}^{+} / \mathrm{H}^{+}$ exchanger 1; NOX, NADPH oxidase; Nrf2, NF-E2 related factor-2; PD, Parkinson's disease; ROS, reactive oxygen species; SDF, stromal cell-derived factor; $\mathrm{SO}_{2} \mathrm{H}$, sulfinic acid; $\mathrm{SO}_{3} \mathrm{H}$, sulfonic acid; $\mathrm{SOH}$, sulfenic acid; Syk, spleen tyrosine kinase; TCR, T cell receptor; TLR, Toll-like receptor; Trx1, thioredoxin 1; WT, wild-type. localization of DJ-1 and inhibits fibrillation of $\alpha$-synuclein (2628). Additionally, the cytoprotective interaction of DJ-1 with apoptosis signal-regulating kinase 1 (ASK1) was mediated by $\mathrm{SO}_{2} \mathrm{H}$ and modulated by peripheral $\mathrm{C} 46$ and $\mathrm{C} 53(29,30)$. However, high oxidation of $\mathrm{C} 106$ to $\mathrm{SO}_{3} \mathrm{H}$ results in aggregated and inactive DJ-1, and has been correlated with the increased progression of disease including PD where oxidative stress is a part of the pathophysiology $(27,31)$.

The reduced form of DJ-1 exerts various functions in addition to eliminating excessive ROS. In terms of DJ-1-dependent activation of dopamine biosynthesis by two enzymes, tyrosine hydroxylase and levodopa decarboxylase, DJ-1 possessing reduced and $\mathrm{SOH}$ forms of $\mathrm{C} 106$ is active and binds to two enzymes, positively regulating their activities (32). Moreover, the reduced form of DJ-1 is required for interaction with phosphatase and tensin homolog and inhibits its phosphatase activity in NIH3T3 fibroblasts, which is not sustained with prolonged oxidative stress and highly oxidized forms of DJ-1 (33). A recent study reported that the direct binding between reduced DJ-1 and Lyn kinase is an indispensable step for full Lyn activation and IgE-mediated stimulation in human MCs, indicating that MC signaling is largely unrelated to DJ-1 antioxidant activity (34).

\section{DJ-1 as a Regulator of Mitochondrial Homeostasis}

Under physiological conditions, DJ-1 is predominantly present in the cytoplasm and, to a lesser extent, in the nucleus and mitochondria including the outer membrane, matrix, and intermembrane space of mitochondria $(26,35)$. However, upon oxidative stress, cytoplasmic DJ-1 translocates to the mitochondria and subsequently to the nucleus, while mitochondrial localized DJ-1 exhibits stronger cytoprotective effects against oxidative stress than cytosolic or nuclear DJ-1 (36). The capability of immediate redistribution of DJ-1 according to changes in the microenvironment is crucial for regulating mitochondrial homeostasis and function, coinciding with cytoprotective activity $(26,36,37)$. Studies have shown that loss of DJ-1 leads to mitochondrial dysfunction including decreased respiratory control ratio, mitochondrial membrane potential, ATP levels, and impaired dynamics, in vitro and in vivo (37-40).

The mitochondrial translocation of DJ-1 is likely mediated by chaperones in response to oxidative stress (41). DJ-1 colocalizes with heat shock protein 70 (Hsp70) in the cytoplasm and is associated with $\mathrm{mtHsp} 70 / \mathrm{Grp} 75$, a mitochondria-resident Hsp70 (41). Therefore, DJ-1 homodimers translocate to the mitochondria by binding to Hsp70 to prevent oxidative stress-induced cell death and maintain mitochondrial homeostasis. However, a recent study showed that Bcl-2associated athanogene 5 interacts with DJ-1 and attenuates the DJ-1-mediated protection of mitochondria, probably by shifting the subcellular distribution of DJ-1 and affecting its dimerization (42).

Moreover, there are also some possible targets of DJ-1 existing in the mitochondria, in particular mitochondrial complex I (43). It has been revealed that DJ-1 directly interacts with complex I subunits NDUFA4 and ND1, and the binding is enhanced under 
oxidative stress. In addition, complex I activity was shown to be reduced in DJ-1-knockdown NIH3T3 and human embryonic kidney 293 cells (43). Based on these findings, we speculate that DJ-1 is an integral mitochondrial protein that plays a role in maintaining mitochondrial homeostasis, including the integrity and activity of complex I.

\section{DJ-1 as a Regulator of Antioxidant Gene Expression}

DJ-1 also acts as an antioxidant by upregulating antioxidant gene expression, in particular through the transcription factor NF-E2 related factor-2 (Nrf2), a critical inducer of antioxidantresponsive element (ARE)-mediated expression. Previous studies have shown that DJ-1 plays a role in stabilizing Nrf2 by affecting association with its repressor Kelch-like ECH-associated protein 1 (Keap1), and the subsequent ubiquitination of Nrf2 (44). The results of a recent finding supported the fact that DJ1 promotes Nrf2-Keap1 dissociation, accounting for enhanced levels of nuclear translocation and ARE binding of Nrf2 in H9c2 cells when exposed to oxidative stress (44). In addition, an in vivo mouse kidney study reported that $\mathrm{Nrf2}$ ubiquitination was increased in DJ-1 knockout (KO) mice compared with wildtype (WT) littermates (45). DJ-1 is responsible for the expression of several Nrf2 target genes including antioxidant enzyme $\mathrm{NAD}(\mathrm{P}) \mathrm{H}$ quinone oxidoreductase 1 and heme oxygenase-1, and products that contribute to the redox reaction such as thioredoxin 1 (Trx1) and glutathione (44-47).

However, some studies have indicated that activation of the Nrf2-ARE pathway is independent of DJ-1, and therefore it has been suggested that Nrf2 is a downstream effector of DJ1 function (48). DJ-1 stimulates nuclear translocation of Nrf2 and enhances its recruitment to the Trx1 promoter (47). A study showed that DJ-1 had no influence on the binding between Nrf2 and Keap1 and ubiquitination state of Nrf2, indicating that DJ1 functions through a non-Keap1-dependent mechanism (47). Consistent with this notion, downregulation of DJ-1 did not impair the Nrf2-Keap1 association in normal human corneal endothelial cells (49). Taken together, DJ-1 can exert antioxidant function by upregulating Nrf2 activation (Figure 1); however, the precise mechanisms need further research.

\section{DJ-1 as a Regulator of Oxidative Stress-Induced Apoptosis}

DJ-1 plays a key role in regulating oxidative stress-induced apoptosis, especially preventing ASK1 activation through multiple mechanisms. First, DJ-1 can stabilize the inhibitory complex of Trx1-ASK1 (Figure 1). Under normal conditions, ASK1 is bound by Trx1 equally with or without DJ-1 overexpression (30). However, upon oxidative stress, Trx1 releases ASK1, a process that is suppressed by overexpression of DJ-1 (30). DJ-1 KO mouse brain homogenates are more susceptible to $\mathrm{H}_{2} \mathrm{O}_{2}$-mediated dissociation of Trx1-ASK1 complex compared with WT brains (30). In addition, DJ-1 can upregulate Trx1 expression through the Nrf2 pathway (Figure 1), thus enhancing intracellular levels of $\operatorname{Trx} 1$ and repressing ASK1 activation (47). Second, DJ-1 may disrupt
ASK1 homodimerization through physical interaction, leading to inhibition of the ASK1 signaling pathway (Figure 1) (50). Of interest, one study suggested that $\mathrm{H}_{2} \mathrm{O}_{2}$ did not significantly impair the cytoplasm colocalization of ASK1 and DJ-1, while other studies have found that oxidative stress and DJ-1 with oxidized C106 are required for DJ-1/ASK1 association $(29,50,51)$. Third, DJ-1 binds to death-associated protein 6 (Daxx) in the nucleus, blocking its translocation to the cytoplasm where Daxx activated its effector kinase ASK1 and the resulting apoptosis (Figure 1) (52, 53). Moreover, p38-regulated/activated kinase may be the essential partner of DJ-1, which induces DJ-1 to sequester Daxx in the nucleus and modulates oxidative stress-induced ASK1 activation (Figure 1) $(53,54)$.

\section{ROLE OF DJ-1 IN THE PATHOPHYSIOLOGY OF IMMUNE AND INFLAMMATORY DISEASES}

\section{DJ-1 and Sepsis}

Sepsis, defined as a life-threatening, multiorgan dysfunction caused by a dysregulated host response to infection, remains the most leading cause of morbidity and mortality in intensive care units worldwide $(55,56)$. It is recently clear that sepsis features concomitant occurrence of excessive inflammation and immune suppression (57). Earlier diagnosis based on routine microbiologic cultures has been proposed in the "Surviving Sepsis" guidelines, which is key to antimicrobial therapy and improved outcomes of clinically ill patients (58). However, many cases have occurred that fail to identify the infecting organism and the inflammatory reaction often sustains after treatment of the infection, which is related to tissue damage and organ failure due to lack of effective therapy and supportive care $(57,59)$.

Macrophages play a crucial part in host immune and inflammatory response during all phases of sepsis. After infection, the activation of macrophages is mediated by a Toll-like receptor (TLR) that recognizes pathogen-associated molecular patterns, including LPS of gram-negative bacteria. In the early stage of sepsis, macrophages undergo M1 polarization and maintain a homeostasis by eliminating pathogens or damaged tissues and producing pro-inflammatory mediators (60). However, if the infection persists, macrophages can polarize toward the M2 phenotype and the host may present a LPStolerant state, leading to severe immunosuppressive stage of sepsis with deleterious consequences (61).

Cellular redox status plays a complicated role in the host immune response and outcomes of sepsis (62). Although excess ROS causes oxidative stress and cell injury, appropriate levels of ROS can initiate various signal transduction cascades that contribute to the bactericidal ability of macrophages and regulation of inflammatory reaction in host response $(63,64)$. Previous studies have shown that ROS is involved in modulating LPS-induced TLR4 trafficking to lipid rafts and subsequent TLR4 activation, as well as downstream signaling pathways in macrophages, such as mitogen-activated protein kinases (MAPKs) and nuclear factor kappa B (NF- $\mathrm{B})$ pathways (65, 


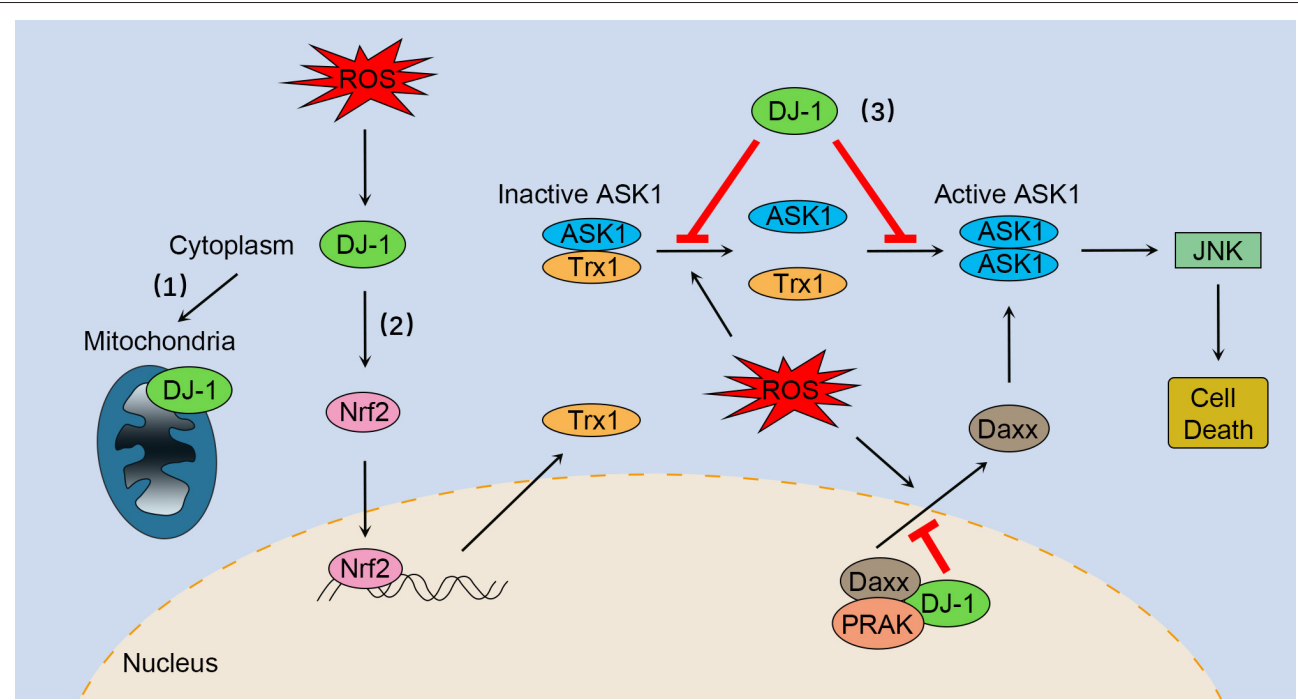

FIGURE 1 | The multifaceted roles of DJ-1 as an antioxidant under oxidative stress. (1) DJ-1 translocates to the mitochondria and maintains mitochondrial homeostasis. (2) DJ-1 exerts antioxidant function by upregulating Nrf2 activation. (3) DJ-1 prevents oxidative stress-induced ASK1 signaling pathways by several mechanisms, including stabilizing the Trx1-ASK1 complex, increasing the expression of Trx1, disrupting ASK1 homodimerization through direct interaction, as well as sequestering the ASK1 activator Daxx in the nucleus. Nrf2, NF-E2 related factor-2; ASK1, apoptosis signal-regulating kinase 1; Trx1, thioredoxin 1; Daxx,

death-associated protein 6; PRAK, p38-regulated/activated kinase; JNK, c-Jun N-terminal kinase.

66). Other studies have suggested that NADPH oxidase (NOX)dependent ROS generation plays a critical role in this process, as TLR4 signaling and pro-inflammatory cytokine production are promoted by NOX activator but are suppressed by a NOX inhibitor (65). In addition, TLR4/NF- $\kappa \mathrm{B}$ activation is involved in M1 macrophage polarization while the downregulated NF- $\kappa$ B pathway is connected to M2 polarization $(67,68)$.

DJ-1 has versatile functions and is distinguished as an antioxidant by multiple mechanisms. However, DJ-1 facilitates NOX-dependent ROS production in early active macrophages through direct interaction with $\mathrm{p} 47^{\mathrm{phox}}$, a subunit of NOX, leading to pro-inflammatory cytokine release (69). Compared with WT mice, $D J-1^{-/-}$mice present with blunt TLR signaling that consequently impairs the bactericidal ability of macrophages, along with decreased local inflammation, and significantly increases mortality in a sepsis model (69). In addition, macrophages with restored DJ-1 expression were shown to rescue ROS generation and enhance survival in LPS-induced sepsis (69), suggesting that DJ-1 has a protective role during sepsis by controlling macrophage activation.

Interestingly, a recent study revealed that DJ-1/p47phox binding disrupted the stability of the NOX complex and promoted subunit $\mathrm{gp} 91^{\text {phox }}$ ubiquitination, thus influencing the optimal ROS production for bacterial clearance and M1 differentiation of macrophages (12). DJ-1 ${ }^{-/-}$mice exhibited elevated levels of pro-inflammatory mediators and improved survival and organ function compared with WT mice, and adoptive transfer of $D J-1^{-/-}$bone marrow-derived mononuclear cells rescued WT mice from septic mortality (12). Additionally, circulating DJ-1 levels were increased and correlated with severity of sepsis and organ dysfunction in patients (12). Based on these findings, DJ-1 seems to act as a potent antioxidant that impairs optimal ROS levels for bacterial killing of macrophages and clinical outcomes of sepsis.

It remains unclear how DJ-1 differs in the above two sepsis studies concerning its functional and molecular outcomes. In the active state of macrophages, DJ-1 probably exerts protective functions through NOX-dependent ROS production against sepsis to facilitate TLR4/MAPKs and/or TLR4/NF-кB signaling pathways, resulting in releasing pro-inflammatory mediators, killing bacteria, and polarizing to the M1 phenotype. However, available DJ-1 functions as an antioxidant in cellular negative feedback to protect from oxidative stress and excessive inflammatory response. DJ-1 can reduce ROS at least through binding to $\mathrm{p} 47^{\mathrm{phox}}$, disrupting NOX stability and its ROS generating capacity, thereby impairing TLR4 activation and downstream signaling pathways. A schematic diagram of our proposed mechanism is presented in Figure 2.

Since one study revealed that the C-terminus of DJ-1 is required for the DJ-1/p47phox interaction (69), we consider that the different consequences of the physical association may be regulated or determined by the oxidation state of DJ-1, in particular C106 oxidation. In addition, we believe that the role of DJ-1 in sepsis is not limited to the DJ-1/p47phox $/$ ROS axis. Rather, mitochondrial ROS are recognized as essential components of the innate immune response and bactericidal activity of macrophages (70).

Taken together, given the effects of DJ-1 on host immune defense by regulating ROS generation of macrophages, the pathophysiology of DJ-1 in sepsis remains to be revealed and the DJ- $1 /$ p $47^{\text {phox }} /$ ROS axis may become a potential therapeutic target to modulate the development of sepsis. 


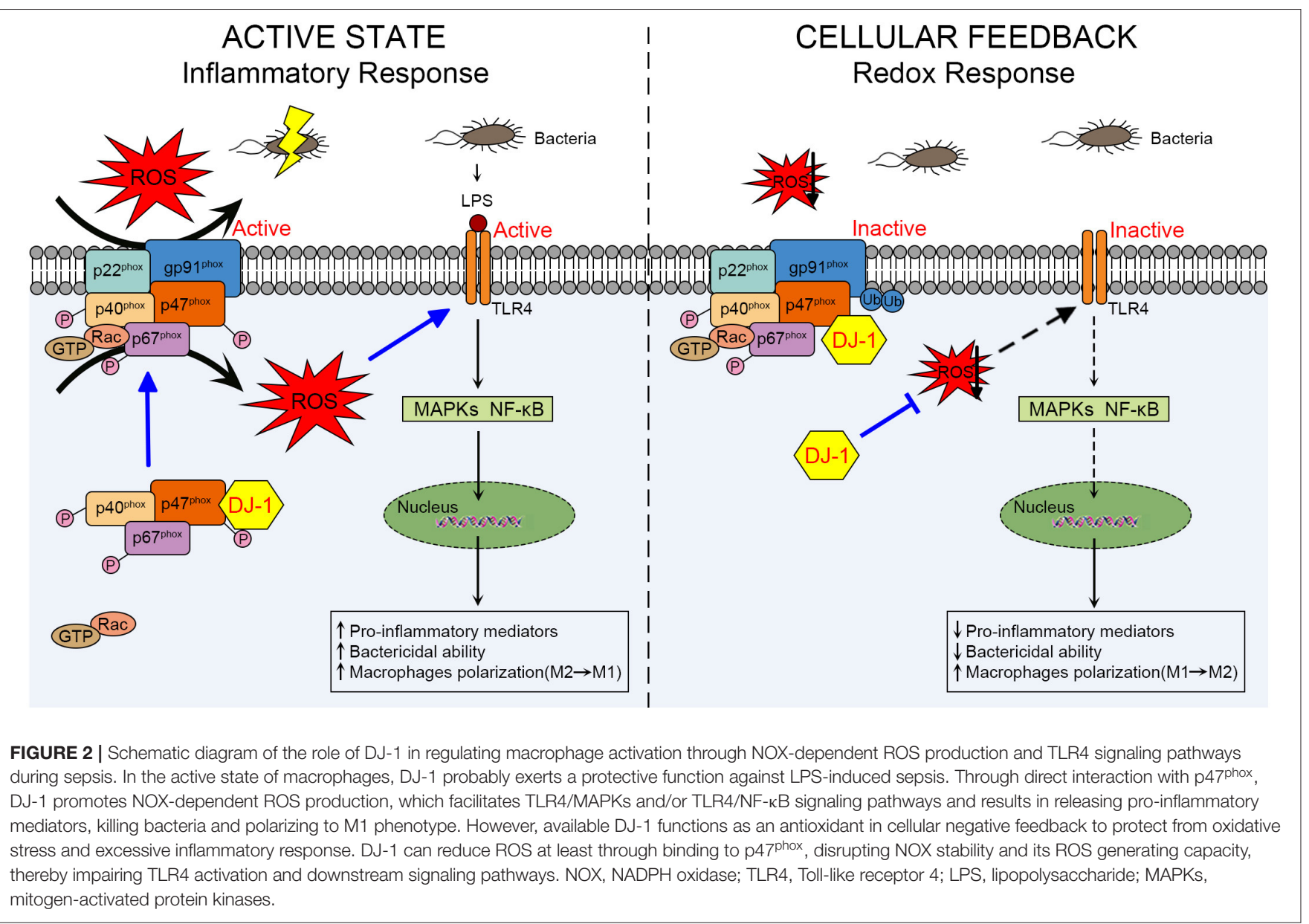

\section{DJ-1 and Allergic Diseases}

IgE-mediated allergic diseases, such as asthma, rhinitis, and atopic dermatitis $(\mathrm{AD})$, are mainly driven by $\mathrm{MCs}(71,72)$. When the high-affinity IgE receptor FceRI of MC surface is aggregated by multivalent antigen, the Src family tyrosine kinases are activated, in particular Lyn, leading to the recruitment and activation of spleen tyrosine kinase (Syk) and downstream signaling cascades, which ultimately causes the release of bioactive and inflammatory mediators $(72,73)$. In addition, other Src family kinases, such as Fyn, are also involved in antigeninduced MC activation (74).

ROS plays a role in modulating MC activation in both innate and acquired immune response, including allergic inflammatory reactions (75). Activated MCs promote the generation of ROS and inflammatory mediators through FceRI cross-linking in response to antigen stimulation $(76,77)$. Diminished levels of DJ-1 and increased levels of ROS have been found in allergic patients with AD (14). Additional studies have shown that DJ-1 KO mice present with enhanced passive cutaneous anaphylaxis reactions and MC degranulation, compared with WT mice (14). In addition, lack of DJ-1 augments ROS generation and cytokine production in antigen-stimulated MCs (14). It has been suggested that DJ-1 deficiency causes excessive ROS levels in MCs, which differentially regulate the activation of Fyn and Syk (14). Therefore, DJ-1 modulates antigen-induced MC activation and allergic responses through ROS-dependent signal transduction cascades.

Of interest, a recent report showed that DJ-1 regulated human MC signaling by partially ROS-independent mechanisms (34). The study revealed that non-oxidized DJ-1 translocated and interacted directly with Lyn in lipid rafts after FceRI engagement, initiating Lyn activation and downstream signaling pathways, but was only specific for human (34). Subsequently, cellular DJ-1 was oxidized along with the decline of ROS levels, thus preventing Syk deactivation to perpetuate MC signaling (34). Based on these findings, DJ-1 plays a unique dual role in FceRI-activated human MC responsiveness, although the precise mechanisms are not completely clear. We speculate that lipid modification especially palmitoylation of three cysteine residues $(\mathrm{C} 46 / 53 / 106)$ may be required for DJ-1 redistribution to lipid rafts and the C-terminal domain of DJ-1 may be required for interaction with Lyn.

Collectively, through ROS-dependent and/or ROSindependent mechanisms, DJ-1 is a vital regulator of MC-derived allergic disorders. In terms of an ROS-dependent 


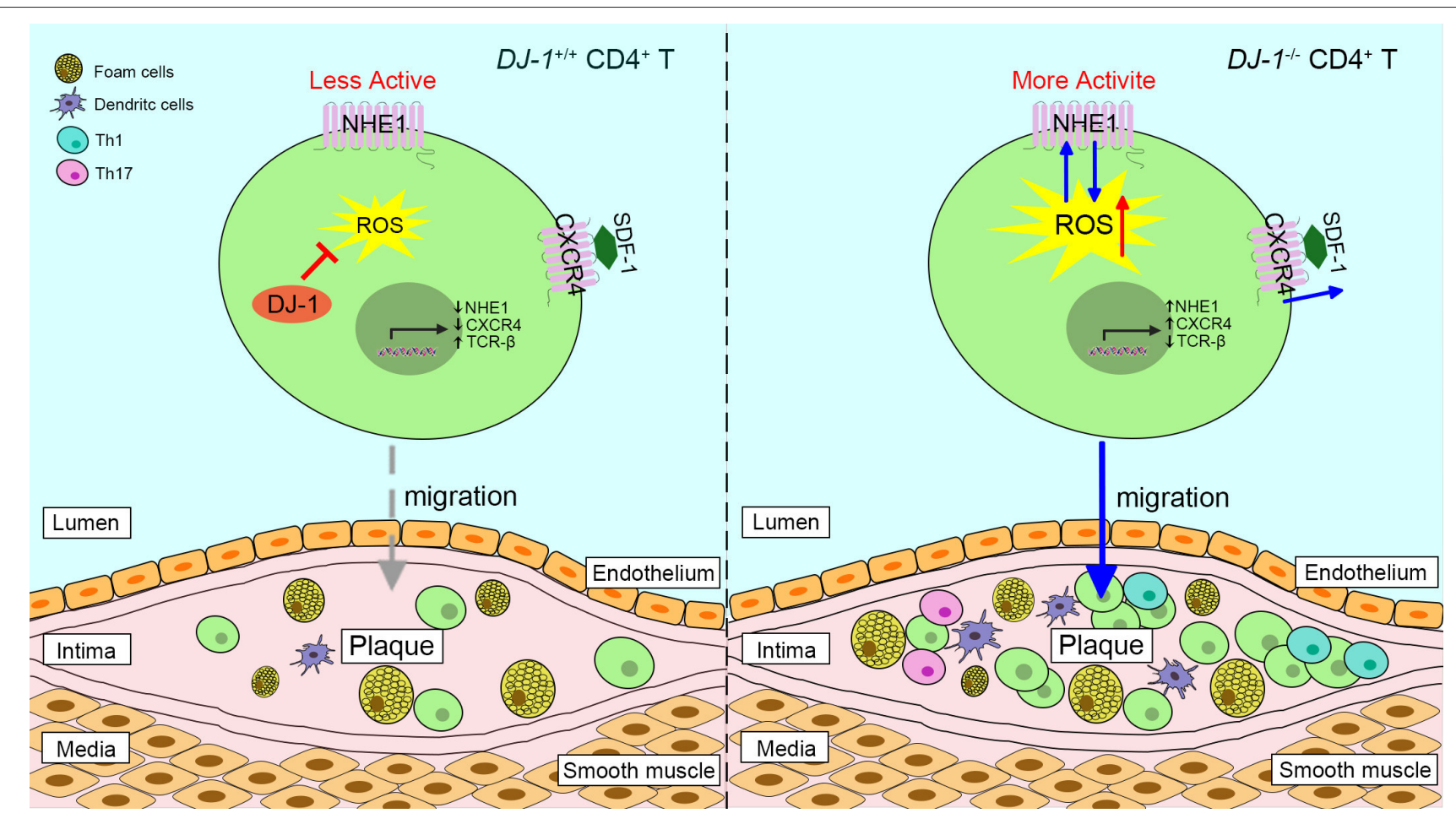

FIGURE 3 | Proposed scheme of the role of DJ-1 in atherosclerosis plaques progression. Absence of DJ-1 leads to excess ROS, which could promote the expression and activity of NHE1 as well as the activity of CXCR4 in response to SDF-1, thus driving CD4+ T cell migration and infiltration into intima. In addition, DJ-1-deficient $\mathrm{CD}^{+} \mathrm{T}$ cells are prone to differentiate into pro-inflammatory Th1 and Th17 phenotypes. Therefore, lack of DJ-1 contributes to atherosclerosis plaque progression. NHE1, $\mathrm{Na}^{+} / \mathrm{H}^{+}$exchanger 1 ; CXCR4, chemokine receptor 4; SDF-1, stromal cell-derived factor 1.

mechanism, whether abnormal DJ-1/ROS levels influence other MC-involved immune and inflammatory response needs further investigation. Concerning the ROS-independent mechanism, the DJ-1/Lyn association proposes new therapeutic modalities for human allergic diseases or possibly other Lyn-mediated disorders.

\section{DJ-1 and AS}

AS, a chronic inflammatory disease, is triggered by genetic susceptibility and environmental risk factors, which is the main pathological basis of ischemic cardio-cerebrovascular diseases, including coronary artery disease $(78,79)$. Accumulating evidence has demonstrated the essential role of $\mathrm{T}$ cells as drivers and modifiers in AS (80). Mass cytometry has characterized distinct $\mathrm{CD}^{+} \mathrm{T}$ cells that were activated and differentiated by $\mathrm{T}$ cells in human AS plaque tissue (81). After migration toward the activated endothelial layer, $\mathrm{CD}^{+} \mathrm{T}$ cells are critical for local antigen-presenting cells within early intimal fatty streaks, such as dendritic cells and macrophages and associated inflammation and AS progression $(82,83)$.

Studies have shown that $D J-1^{-/-}$mice present with higher levels of neointimal plaque formation and increased accumulation of $\mathrm{CD}^{+} \mathrm{T}$ cells in the plaque formed by carotid artery ligation, compared with WT mice $(13,84)$. It is likely triggered by the elevated proliferation of DJ-1 deficient $\mathrm{CD}^{+} \mathrm{T}$ cells and enhanced migration in response to stromal cell-derived factor-1 via overexpression of chemokine receptor $4(13,85)$. In addition, a new relationship between the DJ-1-ROS- $\mathrm{Na}^{+} / \mathrm{H}^{+}$ exchanger 1 (NHE1) revealed that DJ-1-deficient $\mathrm{CD}^{+} \mathrm{T}$ cells upregulated the expression and activity of NHE1, which may have resulted from enhanced ROS generation (86). In turn, NHE1 activity can impair ROS production (86). In this respect, lack of DJ-1 promotes neointima formation since NHE1 contributes to cell migration (87). Of interest, DJ-1 may take a part in the redox regulation of $\mathrm{T}$ cell receptor (TCR) signaling. The expression of TCR signaling proteins such as CD3 and TCR- $\beta$ is dramatically diminished in DJ1-deficient activated $\mathrm{T}$ cells, while co-stimulatory $\mathrm{CD} 28$ is upregulated (86). Moreover, DJ-1-deficient $\mathrm{CD}^{+} \mathrm{T}$ cells show more potential to differentiate into pro-inflammatory Th1 and Th17 phenotypes in an AS model (Figure 3) (13). Taken together, it appears that DJ-1 is a negative regulator of $\mathrm{CD}^{+} \mathrm{T}$ cell migration and activation, thereby suppressing AS pathology.

\section{DJ-1 and MS}

MS is a chronic autoimmune disease of the central nervous system with no cure currently, which is triggered by various environmental factors in genetically susceptible individuals 
$(88,89)$. Recent literature suggests that astrocytes play dual roles in the evolution of MS lesions. They not only adopt a neurotoxic phenotype and act as immunocompetent cells but also promote neuroprotection and axonal preservation (90). Emerging evidence has revealed that ROS has implications in the pathology of MS and experimental autoimmune encephalomyelitis (EAE), the most widely used animal model of MS, and contributes to demyelination and axonal damage of the central nervous system (91-93).

Previous studies have shown that the expression of DJ1 is upregulated in the brains of EAE mice as well as the cerebrospinal fluid from relapsing-remitting MS patients, along with increased disease severity $(94,95)$. Active astrocytes express higher levels of DJ-1 and Nrf2 in both active and chronic inactive MS lesions, compared with control brain tissue and normal-appearing white matter (96). In addition, DJ-1-deficient astrocytes are prone to enhanced inflammation, including cytokine production and oxidative stress $(97,98)$. Based on these findings, we consider that DJ-1 may participate in astrocytemediated protective effects in MS that are at least partially dependent on Nrf2 signaling pathways. However, endogenous regulation is not sufficient to prevent ROS-induced cellular damage, which is abundant in inflammatory MS lesions. In this respect, molecules that target $\mathrm{DJ}-1 / \mathrm{Nrf} 2$ signaling may ameliorate MS development, since dimethyl fumarate that has been FDA-approved for the treatment of MS can upregulate Nrf2 in astrocytes.

\section{DJ-1 AS A SECRETORY PROTEIN}

Previous studies have shown that DJ-1 is a secretory protein and can serve as a biomarker of cancer, stroke, and early phases of $\mathrm{PD}$, which could be beneficial for diagnosis, monitoring, and prognosis (99-101). As mentioned above, plasma DJ-1 protein levels are increased and correlate with sepsis severity and poor clinical outcomes in patients (12). DJ-1 levels are upregulated in the cerebrospinal fluid from MS patients and may have implications with disease progression (95). In FceRIactivated human MCs, total intracellular expression of DJ-1 does not change but DJ-1 with oxidized C106 is upregulated, coinciding with both DJ-1 secretion and diminished intracellular ROS levels (14). In addition, oxidized forms of DJ-1 are preferentially secreted through microdomains and the amounts of extracellularly secreted DJ-1 are only a fraction of the cellular DJ-1 content $(34,102)$. However, diminished levels of DJ-1 and increased levels of ROS are found in $\mathrm{AD}$ patients compared with healthy volunteers, in which alterations are not related to disease severity (14). To the best of our knowledge, DJ-1 can be secreted from various cells because of its ubiquitous expression, but the precise mechanisms remain unknown. Under stress conditions, DJ-1 acts as a sensor and plays a role in regulating cell responses. Damaged cells most likely upregulate the expression of DJ-1 and secrete it in order to attenuate environmental and intracellular oxidative stress at least by self-oxidation to maintain homeostasis (103). Therefore, it will be of clinical importance to determine if secretion of DJ-1 has any disease-specific role or function.

\section{PERSPECTIVES ON DJ-1 AS A THERAPEUTIC TARGET OF IMMUNE AND INFLAMMATORY DISEASES}

Here, we reviewed the critical roles of DJ-1 in several immune and chronic inflammatory diseases. The high levels of DJ-1 could be a candidate biomarker for sepsis and MS, while the extent of DJ-1/ROS abnormality might be relevant to the onset of $\mathrm{AD}$. Taking into consideration that the pivotal functions of DJ-1 involved with activation of macrophages, MCs and $\mathrm{T}$ cells, it is a promising therapeutic target for various immune and inflammatory diseases. Although there is no clinical drug targeting DJ-1 for immunotherapy, we can comment on potential treatment strategies for future directions.

As discussed above, DJ-1 can act as an antioxidant against oxidative stress and prevent the development of AS and MS. DJ-1-binding compounds, including UCP0045037/compound A, UCP0054278/compound B, and compound-23 identified from the university compound library and zinc compound library, prevent superfluous oxidation of DJ-1 and maintain reduced DJ-1, which inhibits oxidative stress-induced toxicity in in vitro and in vivo PD and stroke models (104, 105). Recently, a DJ-1-based peptide named ND-13 was found to protect cultured cells against oxidative insults through activating Nrf2 signaling and significantly improve outcomes in a mouse model of PD (106). In addition, some drugs or drug candidates have also been studied to test their capability of facilitating DJ-1 expression or activation. For example, sodium phenylbutyrate, a histone deacetylase inhibitor, is reportedly neuroprotective in several neurodegenerative disease animal models (107). Other studies have revealed that sodium phenylbutyrate upregulates DJ-1 expression in both cultured cells and mice brains, which is required for its broad protection from metabolic insults (107). Therefore, these compounds/molecules represent potential therapeutic modalities for AS and a wide range of neurodegenerative diseases, including MS, since they can cross the blood-brain barrier and exert protective effects against oxidative stress.

In macrophage-involved sepsis, the DJ-1/p47phox interaction is a decisive factor in regulating ROS-dependent macrophage activation and LPS-responsiveness. It is of great significance to unveil the relative influence of cellular context that leads to different consequences of DJ$1 / \mathrm{p} 47^{\text {phox }}$ interaction, as well as the crystal structure of the DJ-1/p47phox complex. After solving these problems, the DJ$1 /$ p $47^{\text {phox }} /$ ROS axis may become an effective therapeutic target for sepsis.

In human allergic diseases, DJ-1 was identified as a central regulator of $\mathrm{MC}$ activation in response to antigen stimulation (34). Allergic inflammatory responses such as degranulation, cytokines, and eicosanoid production of human MCs were inhibited after transfecting into DJ-1-targeted short hairpin RNAs, suggesting that transcriptional knockdown of DJ-1 using short hairpin RNAs may be an effective strategy to treat 
DJ-1-dependent human allergic disorders (34). In addition, further characterization of DJ-1/Lyn interaction may open novel avenues of therapeutic options in MC-mediated immune and inflammatory diseases.

\section{AUTHOR CONTRIBUTIONS}

QW conceived the review article and made the corrections in the manuscript. BY and $\mathrm{QH}$ provided some critical comments. LZ

\section{REFERENCES}

1. Nagakubo D, Taira T, Kitaura H, Ikeda M, Tamai K, Iguchi-Ariga SMM, et al. DJ-1, a novel oncogene which transforms mouse NIH3T3 cells in cooperation with ras. Biochem Biophys Res Commun. (1997) 231:50913. doi: 10.1006/bbrc.1997.6132

2. Bonifati V, Rizzu P, van Baren MJ, Schaap O, Breedveld GJ, Krieger E, et al. Mutations in the DJ-1 gene associated with autosomal recessive early-onset parkinsonism. Science. (2003) 299:256-9. doi: 10.1126/science. 1077209

3. Kahle PJ, Waak J, Gasser T. DJ-1 and prevention of oxidative stress in Parkinson's disease and other age-related disorders. Free Radic Biol Med. (2009) 47:1354-61. doi: 10.1016/j.freeradbiomed.2009.08.003

4. Wilson MA. The role of cysteine oxidation in DJ-1 function and dysfunction. Antioxid Redox Signal. (2011) 15:111-22. doi: 10.1089/ars.2010.3481

5. Ariga H, Takahashi-Niki K, Kato I, Maita H, Niki T, Iguchi-Ariga SM. Neuroprotective function of DJ-1 in Parkinson's disease. Oxid Med Cell Longev. (2013) 2013:683920. doi: 10.1155/2013/683920

6. Cao J, Lou S, Ying M, Yang B. DJ-1 as a human oncogene and potential therapeutic target. Biochem Pharmacol. (2015) 93:241-50. doi: 10.1016/j.bcp.2014.11.012

7. Girotto S, Cendron L, Bisaglia M, Tessari I, Mammi S, Zanotti G, et al. DJ1 is a copper chaperone acting on SOD1 activation. J Biol Chem. (2014) 289:10887-99. doi: 10.1074/jbc.M113.535112

8. Yanagisawa D, Kitamura Y, Inden M, Takata K, Taniguchi T, Morikawa $\mathrm{S}$, et al. DJ-1 protects against neurodegeneration caused by focal cerebral ischemia and reperfusion in rats. J Cereb Blood Flow Metab. (2008) 28:56378. doi: $10.1038 /$ sj.jcbfm.9600553

9. An CN, Jiang H, Wang Q, Yuan RP, Liu JM, Shi WL, et al. Downregulation of DJ-1 protein in the ejaculated spermatozoa from Chinese asthenozoospermia patients. Fertil Steril. (2011) 96:19-23 e2. doi: 10.1016/j.fertnstert.2011.04.048

10. Taipa R, Pereira C, Reis I, Alonso I, Bastos-Lima A, Melo-Pires M, et al. DJ-1 linked parkinsonism (PARK7) is associated with Lewy body pathology. Brain. (2016) 139(Pt 6):1680-7. doi: 10.1093/brain/aww080

11. Jain D, Jain R, Eberhard D, Eglinger J, Bugliani M, Piemonti L, et al. Age- and diet-dependent requirement of DJ-1 for glucose homeostasis in mice with implications for human type 2 diabetes. J Mol Cell Biol. (2012) 4:221-30. doi: 10.1093/jmcb/mjs025

12. Amatullah H, Shan Y, Beauchamp BL, Gali PL, Gupta S, MaronGutierrez T, et al. DJ-1/PARK7 impairs bacterial clearance in sepsis. Am J Respir Crit Care Med. (2017) 195:889-905. doi: 10.1164/rccm.201604$0730 \mathrm{OC}$

13. Jung SH, Won KJ, Lee KP, Lee DH, Yu S, Lee DY, et al. DJ-1 protein regulates $\mathrm{CD} 3+\mathrm{T}$ cell migration via overexpression of CXCR4 receptor. Atherosclerosis. (2014) 235:503-9. doi: 10.1016/j.atherosclerosis.2014.05.955

14. Kim DK, Kim HS, Kim AR, Kim JH, Kim B, Noh G, et al. DJ-1 regulates mast cell activation and IgE-mediated allergic responses. J Allergy Clin Immunol. (2013) 131:1653-62. doi: 10.1016/j.jaci.2012.10.012

15. Thierry-Mieg D, Thierry-Mieg J. AceView: a comprehensive cDNAsupported gene and transcripts annotation. Genome Biol. (2006) 7(Suppl. 1):S12.1-4. doi: 10.1186/gb-2006-7-s1-s12

16. Smith N, Wilson MA. Structural biology of the DJ-1 superfamily. Adv Exp Med Biol. (2017) 1037:5-24. doi: 10.1007/978-981-10-6583-5_2 wrote the manuscript. JinW and JiaW collect the related research articles. All authors contributed to manuscript revision, read, and approved the submitted version.

\section{FUNDING}

This work was supported by the National Natural Science Foundation of China (No. 81872878) and the Zhejiang Provincial Natural Science Foundation of China (No. LGF18H310001).

17. Tao X, Tong L. Crystal structure of human DJ-1, a protein associated with early onset Parkinson's disease. J Biol Chem. (2003) 278:313729. doi: 10.1074/jbc.M304221200

18. Honbou K, Suzuki NN, Horiuchi M, Niki T, Taira T, Ariga H, et al. The crystal structure of DJ-1, a protein related to male fertility and Parkinson's disease. J Biol Chem. (2003) 278:31380-4. doi: 10.1074/jbc.M305878200

19. Wilson MA, Collins JL, Hod Y, Ringe D, Petsko GA. The 1.1-A resolution crystal structure of DJ-1, the protein mutated in autosomal recessive early onset Parkinson's disease. Proc Natl Acad Sci USA. (2003) 100:925661. doi: $10.1073 /$ pnas.1133288100

20. Moore DJ, Zhang L, Dawson TM, Dawson VL. A missense mutation (L166P) in DJ-1, linked to familial Parkinson's disease, confers reduced protein stability and impairs homo-oligomerization. J Neurochem. (2003) 87:155867. doi: 10.1111/j.1471-4159.2003.02265.x

21. Mitsumoto A, Nakagawa Y, Takeuchi A, Okawa K, Iwamatsu A, Takanezawa Y. Oxidized forms of peroxiredoxins and DJ-1 on two-dimensional gels increased in response to sublethal levels of paraquat. Free Radic Res. (2001) 35:301-10. doi: 10.1080/10715760100300831

22. Mitsumoto A, Nakagawa Y. DJ-1 is an indicator for endogenous reactive oxygen species elicited by endotoxin. Free Radic Res. (2001) 35:88593. doi: 10.1080/10715760100301381

23. Yokota T, Sugawara K, Ito K, Takahashi R, Ariga H, Mizusawa H. Down regulation of DJ-1 enhances cell death by oxidative stress, ER stress, and proteasome inhibition. Biochem Biophys Res Commun. (2003) 312:13428. doi: 10.1016/j.bbrc.2003.11.056

24. Taira T, Saito Y, Niki T, Iguchi-Ariga SMM, Takahashi K, Ariga H. DJ-1 has a role in antioxidative stress to prevent cell death. EMBO Rep. (2004) 5:213-8. doi: 10.1038/sj.embor.7400074

25. Shinbo Y, Niki T, Taira T, Ooe H, Takahashi-Niki K, Maita C, et al. Proper SUMO-1 conjugation is essential to DJ-1 to exert its full activities. Cell Death Differ. (2006) 13:96-108. doi: 10.1038/sj.cdd.4401704

26. Canet-Aviles RM, Wilson MA, Miller DW, Ahmad R, McLendon $\mathrm{C}$, Bandyopadhyay $\mathrm{S}$, et al. The Parkinson's disease protein DJ-1 is neuroprotective due to cysteine-sulfinic acid-driven mitochondrial localization. Proc Natl Acad Sci USA. (2004) 101:9103-8. doi: 10.1073/pnas.0402959101

27. Zhou W, Zhu M, Wilson MA, Petsko GA, Fink AL. The oxidation state of DJ1 regulates its chaperone activity toward alpha-synuclein. J Mol Biol. (2006) 356:1036-48. doi: 10.1016/j.jmb.2005.12.030

28. Blackinton J, Lakshminarasimhan M, Thomas KJ, Ahmad R, Greggio E, Raza AS, et al. Formation of a stabilized cysteine sulfinic acid is critical for the mitochondrial function of the parkinsonism protein DJ-1. J Biol Chem. (2009) 284:6476-85. doi: 10.1074/jbc.M806599200

29. Waak J, Weber SS, Gorner K, Schall C, Ichijo H, Stehle T, et al. Oxidizable residues mediating protein stability and cytoprotective interaction of DJ-1 with apoptosis signal-regulating kinase 1. J Biol Chem. (2009) 284:1424557. doi: 10.1074/jbc.M806902200

30. Im JY, Lee KW, Junn E, Mouradian MM. DJ-1 protects against oxidative damage by regulating the thioredoxin/ASK1 complex. Neurosci Res. (2010) 67:203-8. doi: 10.1016/j.neures.2010.04.002

31. Kiss R, Zhu M, Jojart B, Czajlik A, Solti K, Forizs B, et al. Structural features of human DJ-1 in distinct Cys106 oxidative states and their relevance to its loss of function in disease. Biochim Biophys Acta Gen Subj. (2017) 1861(11 Pt A):2619-29. doi: 10.1016/j.bbagen.2017.08.017 
32. Ishikawa S, Taira T, Niki T, Takahashi-Niki K, Maita C, Maita H, et al. Oxidative status of DJ-1-dependent activation of dopamine synthesis through interaction of tyrosine hydroxylase and 4-dihydroxyL-phenylalanine (L-DOPA) decarboxylase with DJ-1. J Biol Chem. (2009) 284:28832-44. doi: 10.1074/jbc.M109.019950

33. Kim YC, Kitaura H, Taira T, Iguchi-Ariga SM, Ariga H. Oxidation of DJ-1dependent cell transformation through direct binding of DJ-1 to PTEN. Int J Oncol. (2009) 35:133-41. doi: 10.3892/ijo_00000451

34. Kim DK, Beaven MA, Metcalfe DD, Olivera A. Interaction of DJ-1 with Lyn is essential for IgE-mediated stimulation of human mast cells. J Allergy Clin Immunol. (2018) 142:195-206 e8. doi: 10.1016/j.jaci.2017.08.030

35. Zhang L, Shimoji M, Thomas B, Moore DJ, Yu SW, Marupudi NI, et al. Mitochondrial localization of the Parkinson's disease related protein DJ-1: implications for pathogenesis. Hum Mol Genet. (2005) 14:206373. doi: $10.1093 / \mathrm{hmg} / \mathrm{ddi} 211$

36. Junn E, Jang WH, Zhao X, Jeong BS, Mouradian MM. Mitochondrial localization of DJ-1 leads to enhanced neuroprotection. J Neurosci Res. (2009) 87:123-9. doi: 10.1002/jnr.21831

37. Ashley AK, Hanneman WH, Katoh T, Moreno JA, Pollack A, Tjalkens RB, et al. Analysis of targeted mutation in DJ-1 on cellular function in primary astrocytes. Toxicol Lett. (2009) 184:186-91. doi: 10.1016/j.toxlet.2008.11.008

38. Krebiehl G, Ruckerbauer S, Burbulla LF, Kieper N, Maurer B, Waak J, et al. Reduced basal autophagy and impaired mitochondrial dynamics due to loss of Parkinson's disease-associated protein DJ-1. PLoS ONE. (2010) 5:e9367. doi: 10.1371/journal.pone.0009367

39. Hao LY, Giasson BI, Bonini NM. DJ-1 is critical for mitochondrial function and rescues PINK1 loss of function. Proc Natl Acad Sci USA. (2010) 107:9747-52. doi: 10.1073/pnas.0911175107

40. Irrcher I, Aleyasin H, Seifert EL, Hewitt SJ, Chhabra S, Phillips M, et al. Loss of the Parkinson's disease-linked gene DJ-1 perturbs mitochondrial dynamics. Hum Mol Genet. (2010) 19:3734-46. doi: 10.1093/hmg/ddq288

41. Li HM, Niki T, Taira T, Iguchi-Ariga SM, Ariga H. Association of DJ1 with chaperones and enhanced association and colocalization with mitochondrial Hsp70 by oxidative stress. Free Radic Res. (2005) 39:10919. doi: $10.1080 / 10715760500260348$

42. Qin LX, Tan JQ, Zhang HN, Rizwana K, Lu JH, Tang JG, et al. BAG5 interacts with DJ-1 and inhibits the neuroprotective effects of DJ-1 to combat mitochondrial oxidative damage. Oxid Med Cell Longev. (2017) 2017:5094934. doi: 10.1155/2017/5094934

43. Hayashi T, Ishimori C, Takahashi-Niki K, Taira T, Kim YC, Maita H, et al. DJ-1 binds to mitochondrial complex I and maintains its activity. Biochem Biophys Res Commun. (2009) 390:667-72. doi: 10.1016/j.bbrc.2009.10.025

44. Clements CM, McNally RS, Conti BJ, Mak TW, Ting JP. DJ-1, a cancer- and Parkinson's disease-associated protein, stabilizes the antioxidant transcriptional master regulator Nrf2. Proc Natl Acad Sci USA. (2006) 103:15091-6. doi: 10.1073/pnas.0607260103

45. Cuevas S, Yang Y, Konkalmatt P, Asico LD, Feranil J, Jones J, et al. Role of nuclear factor erythroid 2-related factor 2 in the oxidative stress-dependent hypertension associated with the depletion of DJ-1. Hypertension. (2015) 65:1251-7. doi: 10.1161/HYPERTENSIONAHA.114.04525

46. Bitar MS, Liu C, Ziaei A, Chen Y, Schmedt T, Jurkunas UV. Decline in DJ-1 and decreased nuclear translocation of Nrf2 in Fuchs endothelial corneal dystrophy. Invest Ophthalmol Vis Sci. (2012) 53:5806-13. doi: 10.1167/iovs.12-10119

47. Im J-Y, Lee K-W, Woo J-M, Junn E, Mouradian MM. DJ-1 induces thioredoxin 1 expression through the Nrf2 pathway. Hum Mol Genet. (2012) 21:3013-24. doi: $10.1093 / \mathrm{hmg} / \mathrm{dds} 131$

48. Gan L, Johnson DA, Johnson JA. Keap1-Nrf2 activation in the presence and absence of DJ-1. Eur J Neurosci. (2010) 31:967-77. doi: 10.1111/j.1460-9568.2010.07138.x

49. Liu C, Chen Y, Kochevar IE, Jurkunas UV. Decreased DJ-1 leads to impaired Nrf2-regulated antioxidant defense and increased UV-A-induced apoptosis in corneal endothelial cells. Invest Ophthalmol Vis Sci. (2014) 55:555160. doi: $10.1167 /$ iovs.14-14580

50. Mo JS, Jung J, Yoon JH, Hong JA, Kim MY, Ann EJ, et al. DJ-1 modulates the p38 mitogen-activated protein kinase pathway through physical interaction with apoptosis signal-regulating kinase 1. J Cell Biochem. (2010) 110:22937. doi: $10.1002 /$ jcb. 22530
51. Cao J, Ying M, Xie N, Lin G, Dong R, Zhang J, et al. The oxidation states of DJ-1 dictate the cell fate in response to oxidative stress triggered by 4-hpr: autophagy or apoptosis? Antioxid Redox Signal. (2014) 21:144359. doi: 10.1089/ars.2013.5446

52. Junn E, Taniguchi H, Jeong BS, Zhao X, Ichijo H, Mouradian MM. Interaction of DJ-1 with Daxx inhibits apoptosis signal-regulating kinase 1 activity and cell death. Proc Natl Acad Sci USA. (2005) 102:96916. doi: 10.1073/pnas. 0409635102

53. Karunakaran S, Diwakar L, Saeed U, Agarwal V, Ramakrishnan S, Iyengar $S$, et al. Activation of apoptosis signal regulating kinase 1. (ASK1) and translocation of death-associated protein, Daxx, in substantia nigra pars compacta in a mouse model of Parkinson's disease: protection by alpha-lipoic acid. FASEB J. (2007) 21:2226-36. doi: 10.1096/fj.06-7580com

54. Oh SE, Mouradian MM. Cytoprotective mechanisms of DJ-1 against oxidative stress through modulating ERK1/2 and ASK1 signal transduction. Redox Biol. (2018) 14:211-7. doi: 10.1016/j.redox.2017.09.008

55. Hotchkiss RS, Opal S. Immunotherapy for sepsis-a new approach against an ancient foe. N Engl J Med. (2010) 363:87-9. doi: 10.1056/NEJMcibr1004371

56. Singer M, Deutschman CS, Seymour CW, Shankar-Hari M, Annane D, Bauer $\mathrm{M}$, et al. The third international consensus definitions for sepsis and septic shock (sepsis-3). JAMA. (2016) 315:801-10. doi: 10.1001/jama.2016.0287

57. van der Poll T, van de Veerdonk FL, Scicluna BP, Netea MG. The immunopathology of sepsis and potential therapeutic targets. Nat Rev Immunol. (2017) 17:407-20. doi: 10.1038/nri.2017.36

58. Rhodes A, Evans LE, Alhazzani W, Levy MM, Antonelli M, Ferrer R, et al. Surviving sepsis campaign: international guidelines for management of sepsis and septic shock: 2016. Intensive Care Med. (2017) 43:304-77. doi: 10.1007/s00134-017-4683-6

59. Nannan Panday RS, Lammers EMJ, Alam N, Nanayakkara PWB. An overview of positive cultures and clinical outcomes in septic patients: a subanalysis of the Prehospital Antibiotics Against Sepsis (PHANTASi) trial. Crit Care. (2019) 23:182. doi: 10.1186/s13054-019-2431-8

60. Murray PJ, Wynn TA. Protective and pathogenic functions of macrophage subsets. Nat Rev Immunol. (2011) 11:723-37. doi: 10.1038/nri3073

61. Cheng Y, Marion TN, Cao X, Wang W, Cao Y. Park 7: a novel therapeutic target for macrophages in sepsis-induced immunosuppression. Front Immunol. (2018) 9:2632. doi: 10.3389/fimmu.2018.02632

62. Bime C, Zhou T, Wang T, Slepian MJ, Garcia JG, Hecker L. Reactive oxygen species-associated molecular signature predicts survival in patients with sepsis. Pulm Circ. (2016) 6:196-201. doi: 10.1086/685547

63. Alonso de Vega JM, Diaz J, Serrano E, Carbonell LF. Oxidative stress in critically ill patients with systemic inflammatory response syndrome. Crit Care Med. (2002) 30:1782-6. doi: 10.1097/00003246-20020800000018

64. Pizzolla A, Hultqvist M, Nilson B, Grimm MJ, Eneljung T, Jonsson IM, et al. Reactive oxygen species produced by the NADPH oxidase 2 complex in monocytes protect mice from bacterial infections. J Immunol. (2012) 188:5003-11. doi: 10.4049/jimmunol.1103430

65. Nakahira K, Kim HP, Geng XH, Nakao A, Wang X, Murase N, et al. Carbon monoxide differentially inhibits TLR signaling pathways by regulating ROSinduced trafficking of TLRs to lipid rafts. J Exp Med. (2006) 203:237789. doi: 10.1084/jem. 20060845

66. Powers KA, Szaszi K, Khadaroo RG, Tawadros PS, Marshall JC, Kapus A, et al. Oxidative stress generated by hemorrhagic shock recruits Toll-like receptor 4 to the plasma membrane in macrophages. J Exp Med. (2006) 203:1951-61. doi: 10.1084/jem.20060943

67. Odegaard JI, Chawla A. Mechanisms of macrophage activation in obesityinduced insulin resistance. Nat Clin Pract Endocrinol Metab. (2008) 4:61926. doi: $10.1038 /$ ncpendmet0976

68. Pollard JW. Trophic macrophages in development and disease. Nat Rev Immunol. (2009) 9:259-70. doi: 10.1038/nri2528

69. Liu W, Wu H, Chen L, Wen Y, Kong X, Gao WQ. Park7 interacts with $\mathrm{p} 47$ (phox) to direct NADPH oxidase-dependent ROS production and protect against sepsis. Cell Res. (2015) 25:691-706. doi: 10.1038/cr. 2015.63

70. West AP, Brodsky IE, Rahner C, Woo DK, Erdjument-Bromage H, Tempst $\mathrm{P}$, et al. TLR signalling augments macrophage bactericidal activity through mitochondrial ROS. Nature. (2011) 472:476-80. doi: 10.1038/nature09973 
71. Gilfillan AM, Beaven MA. Regulation of mast cell responses in health and disease. Crit Rev Immunol. (2011) 31:475529. doi: 10.1615/CritRevImmunol.v31.i6.30

72. Kalesnikoff J, Galli SJ. New developments in mast cell biology. Nat Immunol. (2008) 9:1215-23. doi: 10.1038/ni.f.216

73. Gilfillan AM, Rivera J. The tyrosine kinase network regulating mast cell activation. Immunol Rev. (2009) 228:14969. doi: 10.1111/j.1600-065X.2008.00742.x

74. Parravicini V, Gadina M, Kovarova M, Odom S, Gonzalez-Espinosa C, Furumoto $\mathrm{Y}$, et al. Fyn kinase initiates complementary signals required for IgE-dependent mast cell degranulation. Nat Immunol. (2002) 3:7418. doi: $10.1038 /$ ni817

75. Swindle EJ, Metcalfe DD. The role of reactive oxygen species and nitric oxide in mast cell-dependent inflammatory processes. Immunol Rev. (2007) 217:186-205. doi: 10.1111/j.1600-065X.2007.00513.x

76. Brooks AC, Whelan CJ, Purcell WM. Reactive oxygen species generation and histamine release by activated mast cells: modulation by nitric oxide synthase inhibition. Br J Pharmacol. (1999) 128:585-90. doi: 10.1038/sj.bjp.0702838

77. Suzuki Y, Yoshimaru T, Matsui T, Inoue T, Niide O, Nunomura S, et al. Fc epsilon RI signaling of mast cells activates intracellular production of hydrogen peroxide: role in the regulation of calcium signals. I Immunol. (2003) 171:6119-27. doi: 10.4049/jimmunol.171.11.6119

78. Ross R. Atherosclerosis-an inflammatory disease. N Engl J Med. (1999) 340:115-26. doi: 10.1056/NEJM199901143400207

79. Weber C, Noels H. Atherosclerosis: current pathogenesis and therapeutic options. Nat Med. (2011) 17:1410-22. doi: 10.1038/nm.2538

80. Saigusa R, Winkels H, Ley K. T cell subsets and functions in atherosclerosis. Nat Rev Cardiol. (2020). doi: 10.1038/s41569-020-0352-5. [Epub ahead of print].

81. Fernandez DM, Rahman AH, Fernandez NF, Chudnovskiy A, Amir ED, Amadori L, et al. Single-cell immune landscape of human atherosclerotic plaques. Nat Med. (2019) 25:1576-88. doi: 10.1038/s41591-019-0590-4

82. Kyaw T, Bobik A. Early adaptive CD4+ T-cell immunity in atherosclerosis goes local. Cardiovasc Res. (2020) 116:253-5. doi: 10.1093/cvr/cvz269

83. MacRitchie N, Grassia G, Noonan J, Cole JE, Hughes CE, Schroeder J, et al. The aorta can act as a site of naive CD4+ T-cell priming. Cardiovasc Res. (2020) 116:306-16. doi: 10.1093/cvr/cvz102

84. Won KJ, Jung SH, Lee CK, Na HR, Lee KP, Lee DY, et al. DJ-1/park7 protects against neointimal formation via the inhibition of vascular smooth muscle cell growth. Cardiovasc Res. (2013) 97:553-61. doi: 10.1093/cvr/cvs363

85. Singh Y, Chen H, Zhou Y, Föller M, Mak TW, Salker MS, et al. Differential effect of DJ-1/PARK7 on development of natural and induced regulatory $\mathrm{T}$ cells. Sci Rep. (2015) 5:17723. doi: 10.1038/srep17723

86. Zhou Y, Shi X, Chen H, Zhang S, Salker MS, Mack AF, et al. DJ-1/Park7 sensitive $\mathrm{Na}^{+} / \mathrm{H}^{+}$exchanger 1. (NHE1) in $\mathrm{CD}^{+}$T cells. J Cell Physiol. (2017) 232:3050-9. doi: 10.1002/jcp.25516

87. Stock $\mathrm{C}, \mathrm{Sch}$ ab A. Role of the $\mathrm{Na} / \mathrm{H}$ exchanger $\mathrm{NHE} 1$ in cell migration. Acta Physiol. (2006) 187:149-57. doi: 10.1111/j.1748-1716.2006.01543.x

88. Koch-Henriksen N, Sørensen PS. The changing demographic pattern of multiple sclerosis epidemiology. Lancet Neurol. (2010) 9:520-32. doi: 10.1016/S1474-4422(10)70064-8

89. Farh KK, Marson A, Zhu J, Kleinewietfeld M, Housley WJ, Beik S, et al. Genetic and epigenetic fine mapping of causal autoimmune disease variants. Nature. (2015) 518:337-43. doi: 10.1038/nature13835

90. Ponath G, Park C, Pitt D. The role of astrocytes in multiple sclerosis. Front Immunol. (2018) 9:217. doi: 10.3389/fimmu.2018.00217

91. Haider L, Fischer MT, Frischer JM, Bauer J, Hoftberger R, Botond G, et al. Oxidative damage in multiple sclerosis lesions. Brain. (2011) 134(Pt 7):1914-24. doi: 10.1093/brain/awr128

92. Fischer MT, Sharma R, Lim JL, Haider L, Frischer JM, Drexhage J, et al. $\mathrm{NADPH}$ oxidase expression in active multiple sclerosis lesions in relation to oxidative tissue damage and mitochondrial injury. Brain. (2012) $135(\mathrm{Pt}$ 3):886-99. doi: 10.1093/brain/aws012

93. Schuh C, Wimmer I, Hametner S, Haider L, Van Dam AM, Liblau RS, et al. Oxidative tissue injury in multiple sclerosis is only partly reflected in experimental disease models. Acta Neuropathol. (2014) 128:24766. doi: 10.1007/s00401-014-1263-5

94. Lev N, Ickowicz D, Barhum Y, Blondheim N, Melamed E, Offen D. Experimental encephalomyelitis induces changes in DJ-1: implications for oxidative stress in multiple sclerosis. Antioxid Redox Signal. (2006) 8:198795. doi: 10.1089/ars.2006.8.1987

95. Hirotani M, Maita C, Niino M, Iguchi-Ariga S, Hamada S, Ariga $\mathrm{H}$, et al. Correlation between DJ-1 levels in the cerebrospinal fluid and the progression of disabilities in multiple sclerosis patients. Mult Scler. (2008) 14:1056-60. doi: 10.1177/1352458508093616

96. van Horssen J, Drexhage JA, Flor T, Gerritsen W, van der Valk $\mathrm{P}$, de Vries HE. Nrf2 and DJ1 are consistently upregulated in inflammatory multiple sclerosis lesions. Free Radic Biol Med. (2010) 49:1283-9. doi: 10.1016/j.freeradbiomed.2010.07.013

97. Choi DJ, An J, Jou I, Park SM, Joe EH. A Parkinson's disease gene, DJ-1, regulates anti-inflammatory roles of astrocytes through prostaglandin D2 synthase expression. Neurobiol Dis. (2019) 127:48291. doi: 10.1016/j.nbd.2019.04.003

98. Waak J, Weber SS, Waldenmaier A, Gorner K, Alunni-Fabbroni M, Schell $\mathrm{H}$, et al. Regulation of astrocyte inflammatory responses by the Parkinson's disease-associated gene DJ-1. FASEB J. (2009) 23:247889. doi: 10.1096/fj.08-125153

99. Cao J, Chen X, Ying M, He Q, Yang B. DJ-1 as a Therapeutic target against cancer. Adv Exp Med Biol. (2017) 1037:20322. doi: 10.1007/978-981-10-6583-5_13

100. Whiteley W, Tseng MC, Sandercock P. Blood biomarkers in the diagnosis of ischemic stroke: a systematic review. Stroke. (2008) 39:29029. doi: 10.1161/STROKEAHA.107.511261

101. Saito Y. DJ-1 as a Biomarker of Parkinson's disease. Adv Exp Med Biol. (2017) 1037:149-71. doi: 10.1007/978-981-10-6583-5_10

102. Tsuboi Y, Munemoto H, Ishikawa S, Matsumoto K, Iguchi-Ariga SM, Ariga H. DJ-1, a causative gene product of a familial form of Parkinson's disease, is secreted through microdomains. FEBS Lett. (2008) 582:26439. doi: 10.1016/j.febslet.2008.06.043

103. Kawate T, Iwaya K, Koshikawa K, Moriya T, Yamasaki T, Hasegawa S, et al. High levels of DJ-1 protein and isoelectric point 6.3 isoform in sera of breast cancer patients. Cancer Sci. (2015) 106:938-43. doi: 10.1111/cas.12673

104. Kitamura Y, Watanabe S, Taguchi M, Takagi K, Kawata T, TakahashiNiki K, et al. Neuroprotective effect of a new DJ-1-binding compound against neurodegeneration in Parkinson's disease and stroke model rats. $\mathrm{Mol}$ Neurodegener. (2011) 6:48. doi: 10.1186/1750-1326-6-48

105. Miyazaki S, Yanagida T, Nunome K, Ishikawa S, Inden M, Kitamura Y, et al. DJ-1-binding compounds prevent oxidative stress-induced cell death and movement defect in Parkinson's disease model rats. J Neurochem. (2008) 105:2418-34. doi: 10.1111/j.1471-4159.2008.05327.x

106. Finkelstein DI, Lev N, Barhum Y, Ben-Zur T, Aharony I, Trifonov L, et al. A DJ-1 based peptide attenuates dopaminergic degeneration in mice models of Parkinson's disease via enhancing Nrf2. PLoS ONE. (2015) 10:e0127549. doi: 10.1371/journal.pone.0127549

107. Zhou W, Bercury K, Cummiskey J, Luong N, Lebin J, Freed CR. Phenylbutyrate up-regulates the DJ-1 protein and protects neurons in cell culture and in animal models of Parkinson disease. J Biol Chem. (2011) 286:14941-51. doi: 10.1074/jbc.M110.211029

Conflict of Interest: The authors declare that the research was conducted in the absence of any commercial or financial relationships that could be construed as a potential conflict of interest.

Copyright (c) 2020 Zhang, Wang, Wang, Yang, He and Weng. This is an open-access article distributed under the terms of the Creative Commons Attribution License (CC $B Y)$. The use, distribution or reproduction in other forums is permitted, provided the original author(s) and the copyright owner(s) are credited and that the original publication in this journal is cited, in accordance with accepted academic practice. No use, distribution or reproduction is permitted which does not comply with these terms. 